\title{
Serum antimüllerian hormone levels best reflect the reproductive decline with age in normal women with proven fertility: a longitudinal study
}

\author{
Ilse A. J. van Rooij, Ph.D., ${ }^{a}$ Frank J. M. Broekmans, Ph.D.,, Gabrielle J. Scheffer, Ph.D., ${ }^{\mathrm{a}}$ \\ Caspar W. N. Looman, M.Sc., ${ }^{\mathrm{b}}$ J. Dik F. Habbema, Ph.D., ${ }^{\mathrm{b}}$ Frank H. de Jong, Ph.D., ${ }^{\mathrm{c}}$ \\ Bart J. C. M. Fauser, Ph.D. ${ }^{\mathrm{d}}$ Axel P. N. Themmen, Ph.D., ${ }^{\mathrm{c}}$ and Egbert R. te Velde, Ph.D. ${ }^{\mathrm{a}}$ \\ ${ }^{a}$ Department of Reproductive Medicine, University Medical Center Utrecht, Utrecht; and Departments of ${ }^{\mathrm{b}}$ Public Health, ${ }^{\mathrm{c}}$ Internal \\ Medicine, and ${ }^{\mathrm{d}}$ Center of Reproductive Medicine, Erasmus Medical Center, Rotterdam, The Netherlands
}

Objective: The aim of this study was to assess which of the basal ovarian reserve markers provides the best reflection of the changes occurring in ovarian function over time (i.e., reproductive aging).

Design: Prospective longitudinal study.

Setting: Healthy volunteers in an academic research center.

Patient(s): Eighty-one women with normal reproductive performance during the course of their lives were longitudinally assessed. In this select group of women, becoming chronologically older was considered as a proxy variable for becoming older from a reproductive point of view.

Intervention(s): The women were assessed twice, with on average a 4-year interval $\left(T_{1}\right.$ and $\left.T_{2}\right)$. The number of antral follicles on ultrasound (AFC) and blood levels of antimüllerian hormone $(\mathrm{AMH}), \mathrm{FSH}$, inhibin $\mathrm{B}$, and $\mathrm{E}_{2}$ were assessed.

Main Outcome Measure(s): Longitudinal changes of the markers mentioned and the consistency of these parameters over time.

Result(s): The mean ages at $T_{1}$ and $T_{2}$ were 39.6 and 43.6 years, respectively. Although AFC was strongly associated with age in a cross-sectional fashion, it did not change over time. The AMH, FSH, and inhibin B levels showed a significant change over time, in contrast to $\mathrm{E}_{2}$ levels. The AMH and AFC were highly correlated with age both at $T_{1}$ and $T_{2}$, whereas FSH and inhibin B predominantly changed in women more than 40 years of age. To assess the consistency of these parameters over time, we investigated whether a woman's individual level above or below the mean of her age group at $T_{1}$ remained above or below the mean of her age group at $T_{2}$. Serum AMH concentrations showed the best consistency, with AFC as second best. The FSH and inhibin B showed only modest consistency, whereas $\mathrm{E}_{2}$ showed no consistency at all.

Conclusion(s): These results indicate that serum AMH represents the best endocrine marker to assess the age-related decline of reproductive capacity. (Fertil Steril ${ }^{\circledR}$ 2005;83:979-87. ${ }^{\circ} 2005$ by American Society for Reproductive Medicine.)

Key Words: Reproductive aging, AMH, AFC, FSH, inhibin B

With increasing age there is a decline in a woman's reproductive function, which is assumed to be determined by the decline of the ovarian follicle pool and the quality of the oocytes within (ovarian reserve) (1). Menopause is reached at a median age of 51 years, when the follicle pool is (almost) depleted (2). Given the considerable individual variability in age at menopause (3), it is plausible that the process of follicle decline shows a comparable variability.

Received May 26, 2004; revised and accepted November 30, 2004. Reprint requests: Ilse van Rooij, Ph.D., Department of Reproductive Medicine, University Medical Center Utrecht, Heidelberglaan 100, 3584 CX Utrecht, The Netherlands (FAX: 31-30-2505433; E-mail: i.vanrooij@ azu.nl).
Hence, for women of similar ages, large differences in their ovarian reserve are likely to exist.

Various endocrinological and sonographic markers have been used to assess the ovarian reserve. First, an increase in FSH levels in women over 35 years was observed (4). Subsequently, it was shown that inhibin B levels diminished with advancing age, presumably due to a reduction of the recruited cohort of the antral follicle pool during the follicular phase of the cycle (5-7). In addition, changes in $E_{2}$ levels have been described in women of advanced reproductive age. Both an increase (8) and a decline (9) were reported. The size of the antral follicle cohort can be directly assessed by ultrasound (10), and the observed pattern of its decline appears to correspond with that of the primordial 
follicle pool (11). Recently, serum antimüllerian hormone $(\mathrm{AMH})$ levels have been introduced as a novel measure of ovarian reserve. AMH is a product of granulosa cells of the preantral and antral follicles $(12,13)$. Serum AMH levels decline with age and are related to the number of antral follicles and to the ovarian response after ovarian hyperstimulation (14-18).

Previously, we have shown in a cross-sectional study that the number of antral follicles assessed by ultrasonography (AFC) better reflects chronological age in normal women with regular cycles and proven normal fertility (19), compared to other ovarian reserve tests. Because these women were selected on the basis of normal reproductive performance during the course of their lives, it was assumed that their ovarian function reflects the gradual age-related decline of normal reproductive capacity. Therefore, their chronological age was considered to approximate their reproductive age. However, as indicated in such a population the variation of reproductive capacity in women of the same age category is likely to exist.

This previous study was the beginning of a continuing longitudinal study. Women were asked to return every 4 years for a new assessment of their ovarian reserve. With such a design, it is possible to study changes in ovarian reserve markers in a prospective manner in individual women. Because the same assumptions were made for the longitudinal part of this study, becoming 4 years older in chronological age is considered to approximate an increase of 4 years in reproductive age for these women with proven fertility. This present study was designed to assess the change in levels and values of ovarian reserve over time. The aim of the study was to determine which of the ovarian reserve tests presently available best reflects the process of reproductive aging in individual women.

\section{MATERIALS AND METHODS Subjects}

In 1996 and 1997 female volunteers were recruited for a longitudinal cohort study through advertisement in local newspapers. The inclusion criteria have been described before $(11,19)$. In short, the women had to be $25-46$ years of age and to have a regular menstrual cycle of 21-35 days. They had to have a proven natural fertility, which was defined as having established one or more pregnancies within 1 year after stopping contraception. This pregnancy resulted in a normal delivery at term. Moreover, they never had ovarian surgery or ovarian abnormalities and they had stopped hormonal contraception for 3 months or more before entering the study.

Of the 162 volunteers included in 1996-1997 $(11,19), 82$ agreed to continue. The remaining 80 women did not participate in the longitudinal part of this study because they did not want to stop hormonal contraception $(\mathrm{n}=10)$, were pregnant or breastfeeding $(n=3)$, had intercurrent disease $(\mathrm{n}=3)$, had no time $(\mathrm{n}=8)$, or had moved away from the area $(n=37)$. For 19 volunteers the reason for not participating was not known. The women not taking part in the follow-up study were on average 4 years younger than the women who did participate.

The Institutional Review Board approved of the study and written informed consent was obtained from all participants. The volunteers received monetary compensation for participating.

\section{Study Design}

The 82 women participating in this longitudinal study were tested at $T_{1}(1996 / 1997)$ and at $T_{2}(2001)$ during the early follicular phase of the menstrual cycle (cycle days 2, 3, or 4). If at $T_{2}$ no menstrual period had taken place during the past 3 months because menopausal transition had been reached, a visit was planned at the woman's convenience. During both visits a transvaginal ultrasound was performed using a 7.5MHz probe on a Toshiba Capasee SSA-220A (Toshiba Medical Systems Europe BV, Zoetermeer, The Netherlands). At $\mathrm{T}_{1}$ the ultrasound was performed by G.J.S. and at $\mathrm{T}_{2}$ by I.A.J.R. The number of antral follicles was assessed and all follicles up to $10 \mathrm{~mm}$ were included in the analysis, as described previously (11).

During the same visit blood was drawn. Serum and plasma were separated and stored at $-20^{\circ} \mathrm{C}$ for later estimation of levels of $\mathrm{AMH}, \mathrm{FSH}$, inhibin $\mathrm{B}$, and $\mathrm{E}_{2}$. The plasma and serum samples collected at $T_{1}$ and $T_{2}$ of each volunteer were assessed in the same assay run.

Some of the women reached menopausal transition, because cycle irregularity occurred after these women had normal regular cycles when they were included at baseline. There is no available uniform definition for menopausal transition, although recently some definitions based on increasing variability in cycle length have been proposed (20, 21). We defined menopausal transition in two ways. The mean cycle length is between 21 and 35 days, but in the last half year the next cycle is not predictable within 7 days. Or the mean cycle length is $<21$ or $>35$ days in the last half year.

None of the women in the study used hormonal replacement therapy (HT) for menopausal symptoms. Two women stopped hormonal contraception 3 months before inclusion. They regained regular cycles and continued to do so for 6 months.

\section{Assays}

Levels of FSH and $\mathrm{E}_{2}$ were measured in plasma with the AxSYM immunoanalyzer (Abbott Laboratories, Abbott Park, IL). The World Health Organization Second International Reference Preparation for human FSH (78/549) was used as a standard for the FSH assay. For FSH, interassay coefficients of variation were found to be $5.7 \%, 5.7 \%$, and 
$7.8 \%$ at the levels of 5,26 , and $79 \mathrm{IU} / \mathrm{L}$, respectively $(\mathrm{n}=$ 80 ). The $\mathrm{E}_{2}$ assay has been standardized to gas chromatography/mass spectrometry. The interassay variation of the $\mathrm{E}_{2}$ assay at 185,330 , and $1,152 \mathrm{pmol} / \mathrm{L}$ was $12.9 \%, 7.8 \%$, and $5.1 \%$, respectively $(\mathrm{n}=80)$.

Serum inhibin B levels were measured using an immunoenzymometric assay (Serotec, Oxford, United Kingdom) as described by Groome et al. (22). Interassay coefficients of variation were $6.6 \%$ and $6.0 \%$ at 110 and $770 \mathrm{pg} / \mathrm{mL}$. An ultrasensitive immunoenzymometric assay (ImmunotechCoulter, Marseille, France) was used for the estimation of AMH (23). The limit of detection (defined as blank + 3SD) was $0.05 \mu \mathrm{g} / \mathrm{L}$. Intra- and interassay coefficients of variation were $<5 \%$ and $<8 \%$. Long-term storage ( $>2$ years) of blood samples at $-20^{\circ} \mathrm{C}$ before assessment of AMH levels is believed to lead to artificially increased levels (24). However, these suggestions were based on studies with the Boston assay (24). For the Coulter assay as applied in this study, such measurement errors have been excluded as shown elsewhere (14).

\section{Statistical Analysis}

Data were analyzed with SPSS 10.1 (SPSS Inc., Chicago, IL) and presented as mean (SD) if normally distributed or median (10th-90th percentiles) if not normally distributed. Outcomes of the ovarian reserve test with an interval of approximately 4 years $\left(\mathrm{T}_{1}\right.$ and $\left.\mathrm{T}_{2}\right)$ were compared using the Wilcoxon signed rank test.

Because the time interval between $T_{1}$ and $T_{2}$ ranged from 3 to 5 years, the change per year was calculated ([value $T_{2}-$ value $\left.\mathrm{T}_{1}\right] /$ time interval $\mathrm{T}_{2}-\mathrm{T}_{1}$ ) for every woman. The mean change per year with $95 \%$ confidence interval around the mean of each test is given per arbitrary age classes, with age cutoff levels assessed at $T_{1}$. The significance of the mean change was tested by Student's $t$-test.

The associations between the results of the ovarian reserve tests and age both at $T_{1}$ and $T_{2}$ were assessed by a quadratic regression line. If the quadratic regression term on $T_{1}$ or $T_{2}$ was significant, a restricted cubic spline was fitted to describe the relation (25), otherwise a linear relation was assumed. All associations between markers and age were assessed using Spearman correlations.

The analyses mentioned thus far only evaluated mean changes in groups of women. The important question, however, is: what happens in individual women? Most likely they demonstrate considerable variations above and below the mean. For reliable individual predictions it is important to know whether or not these variations remain consistent during two or more observations over time. Therefore, we investigated whether an individual's level above (below) the mean level for her age group at $\mathrm{T}_{1}$ remained above (below) the mean level for her age group at $\mathrm{T}_{2}$. The same rationale has been described by Burger et al. (26).
Because we had only two measurements per woman we made use of the so-called partial correlation coefficient analysis (27). The longitudinal setting leads to a slight adaptation of the procedure, in that we corrected the markers at $\mathrm{T}_{1}$ and $\mathrm{T}_{2}$ separately for age at that time and afterward calculated the correlation coefficient. Thus, the individual value at $T_{1}$ minus the group mean value (on the regression line) for that particular age (the residual) is correlated with the residual at $T_{2}$ (individual value at $T_{2}$ minus the group mean value for age at $\mathrm{T}_{2}$ ). If this correlation is high, the ovarian reserve test is a potentially useful marker for declining ovarian performance because the observation at $T_{1}$ correctly predicts the level at $\mathrm{T}_{2}$.

\section{RESULTS}

Because no serum sample was available from one woman at $\mathrm{T}_{1}, 81$ of the 82 women could be analyzed. Mean (SD) age of the women was $39.6(5.0)$ years at $T_{1}$ and 43.6 (4.9) years at $\mathrm{T}_{2}$. The mean (range) time interval between $\mathrm{T}_{1}$ and $\mathrm{T}_{2}$ was 3.9 (3.0-4.9) years. A total of 67 volunteers still had a regular cycle at $\mathrm{T}_{2}$, but 14 women had entered the menopausal transition.

At $\mathrm{T}_{2}$ the median serum AMH level was significantly lower than at $\mathrm{T}_{1}$ (Table 1). Surprisingly, the AFC remained the same over time. The FSH levels increased significantly, whereas the inhibin $B$ levels significantly declined and the $\mathrm{E}_{2}$ levels did not change. The changes per year of each ovarian reserve marker were assessed in the groups according to age class (Table 2). AMH showed a highly significant change in the two highest age classes and a borderline significant change in the youngest age group. The AFC, inhibin B, and FSH levels only exhibited a significant yearly change per year in women over 40 years of age. This was more marked for FSH and inhibin $\mathrm{B}$, the levels of which considerably changed when age exceeded 40 years. The $\mathrm{E}_{2}$ levels did not show any significant change.

Figure 1 shows the relationships of the ovarian reserve markers with age at $T_{1}$ and at $T_{2}$. For FSH it was necessary to use a fitted line to describe the relation with age at $T_{2}$ when linear regression could not be used. For reasons of comparison a fitted line was used at $\mathrm{T}_{1}$. The antral follicle count showed the highest correlation with age at both time points, followed by serum AMH. The regression line of AFC assessed at $\mathrm{T}_{2}$ was shifted in a parallel fashion and was situated above the line representing the relationship with age at $\mathrm{T}_{1}$, indicating that more antral follicles were counted at $\mathrm{T}_{2}$. At $T_{1}$ FSH increased slightly with age, but at $T_{2}$ this increase was substantial at more than 40 years of age. Inhibin $\mathrm{B}$ showed a significant association with age at $T_{2}$, but not at $T_{1}$. In contrast, $\mathrm{E}_{2}$ showed only a significant relation with age on $\mathrm{T}_{1}$, which disappeared at $\mathrm{T}_{2}$.

The correlation of the residuals for all markers is shown in Table 3. The AMH showed the highest correlation between the age-adjusted values at $T_{1}$ and $T_{2}$. Although AFC showed 


\begin{tabular}{|c|c|c|c|}
\hline \multicolumn{4}{|c|}{$\begin{array}{l}\text { Comparison of ovarian reserve tests over time in normal fertile women ( } T_{1} \text { value and } T_{2} \text { value, } \\
\text { mean time interval } 4 \text { years). }\end{array}$} \\
\hline & $\mathbf{T}_{1}$ & $\mathbf{T}_{2}$ & $P$ value $^{a}$ \\
\hline AMH $(\mu \mathrm{g} / \mathrm{L})$ & $1.2(0.1-3.0)$ & $0.5(0.0-2.2)$ & $<.001$ \\
\hline $\operatorname{AFC}(n)$ & $6(2-16)$ & $6(0-16)$ & .56 \\
\hline FSH (IU/L) & $7.8(4.9-12.7)$ & $8.7(5.2-45.7)$ & $<.001$ \\
\hline Inhibin B (ng/L) & $104(14-160)$ & $78(8-139)$ & .002 \\
\hline $\mathrm{E}_{2}(\mathrm{pmol} / \mathrm{L})$ & 180 (98-353) & 155 (87-292) & .36 \\
\hline \multicolumn{4}{|c|}{$\begin{array}{l}\text { Note: Values are median (10th-90th) percentiles. See text for abbreviations. } \\
\text { a Wilcoxon signed rank test. }\end{array}$} \\
\hline
\end{tabular}

no decline over time, the residuals over time were highly correlated. The correlation of the residuals of FSH and inhibin B were significant, although clearly lower than for $A M H$ and AFC. The residuals of $E_{2}$ at $T_{1}$ and $T_{2}$ were not correlated.

\section{DISCUSSION}

The prevailing concept of female reproductive aging suggests that the decline of the oocyte/follicle pool determines the age-dependent loss of female fertility (1). Because chronological age at the final stage of reproductive aging (i.e., the occurrence of menopause) shows a considerable individual variation, it is most likely that women differ with regard to the status of the oocyte/follicle pool at a given age. Women maintain a regular ovulatory pattern with (almost) normal $\mathrm{E}_{2}$ and $\mathrm{P}$ levels for years after they have become infertile (1). Because it is not feasible to directly assess the oocyte/follicle pool, endocrinological and sonographic markers are used as an indirect measure of the oocyte/follicle pool.

In the current study we evaluated and compared the available basal ovarian reserve tests in a population of women with normal reproductive performance during the course of their lives. In such women the longitudinal changes in ovarian reproductive function during the follow-up period are likely to reflect the normal physiological decline of female fecundity. Chronological age, therefore, was taken as the proxy-variable of reproductive decline and the elapse of some 4 years is considered to be accompanied by a decline in reproductive capacity $(1,11)$.

The requirements for the ideal marker reflecting the decline of reproductive function are summarized in Table 4 . First, it must be biologically plausible that the marker is related to the extent of the oocyte/follicle pool. Second, the marker should be clearly associated with age. Third, it should demonstrate a change over time, preferably from approximately 30 until 50 years of age and not only during or just before the episode of menopausal transition. Most important, the individual variation from the mean should be consistent, that is, the level of an individual above or below the mean at a certain age (the residual value) should remain the same at subsequent ages.

The biological plausibility of the investigated markers is to be judged on their ability to reflect the entire follicle pool. In contrast to AFC and inhibin B $(7,11)$, AMH may not only reflect the number of early and developing antral follicles, but also earlier stages of follicle development, as was shown both in animal and human studies $(12,13,28,29)$. However, the contribution of the different follicle stages to the final serum AMH level is unknown. A recent investigation revealed significantly declining serum AMH levels during ovarian hyperstimulation (18), suggesting that FSH stimulates the differentiation and maturation of the antral follicles to such an extent that they cease to produce $\mathrm{AMH}$, whereas the smaller follicles continue to do so, albeit that their smaller granulosa cell mass results in lower AMH serum levels.

The FSH release by the pituitary gland is regulated by the negative feedback action of inhibins, $E_{2}$, and other ovarian FSH-modulating proteins. Therefore, FSH levels are an indirect reflection of the number of antral follicles (6). The $E_{2}$ levels are less a reflection of the number of antral follicles, but rather of their growth activity during the follicular phase $(4,8)$. On the basis of this reasoning we attributed the highest biological plausibility to $\mathrm{AMH}$, followed by $\mathrm{AFC}$, inhibin $\mathrm{B}, \mathrm{FSH}$, and $\mathrm{E}_{2}$.

With regard to the cross-sectional relationship with age (Fig. 1), AFC correlated somewhat better with age compared to AMH and much better than FSH, inhibin B, and $\mathrm{E}_{2}$ at both times of assessment. Until age 40 years, FSH and inhibin $\mathrm{B}$ levels were not correlated with age, confirming an earlier study reporting on a lack of correlation of FSH and inhibin B with age in women aged 20-35 years (30). At 40 years and even more so at 45 years of age, FSH started to increase substantially, and the highest levels were mainly contributed by women with an irregular cycle. These endocrine changes seem only to occur 
when follicle numbers are strongly reduced (1) just before or during the menopausal transition.

These higher FSH and lower inhibin B levels in older women at $\mathrm{T}_{2}$ led to a much stronger correlation of these two parameters with age, compared to the correlation at $\mathrm{T}_{1}$. At $\mathrm{T}_{1}$ a positive, although low correlation of $\mathrm{E}_{2}$ with age was present, corresponding to the higher $\mathrm{E}_{2}$ production in older women. This is probably caused by advanced follicular growth leading to larger follicles in the early follicular phase (31). However, when more women with an irregular cycle pattern were present in the population (at $\mathrm{T}_{2}$ ), more variation in $\mathrm{E}_{2}$ levels was present and no correlation with age could be detected.

$\mathrm{AMH}$ was the only marker of ovarian reserve showing a mean longitudinal decline over time in the total study population as well as in all separate age classes (Table 2). Even at younger ages a significant decline in AMH levels is present, confirming earlier findings in which AMH was the only marker changing longitudinally in younger women (14). The FSH levels increased and the inhibin B levels decreased over time, but the significant changes were only seen in women over 40 years of age.

Contrary to our expectations, no longitudinal change was observed for AFC (Table 1), although a strong crosssectional relation between AFC and age was present. Antral follicles were counted at $\mathrm{T}_{1}$ and $\mathrm{T}_{2}$ by two different observers, and the second observer appeared to count systematically more follicles, as visualized by the two parallel regression lines for AFC in Figure 1. An assessment bias due to interobserver variability is one of the likely explanations for this finding. However, two separate studies have shown that variability among observers in counting antral follicles is rather modest $(32,33)$. Moreover, a study by de Vet et al. (14) showed that a longitudinal decrease in antral follicle numbers was also absent at a mean time interval of 2 years.

This may imply that antral follicle numbers follow a decline with age that is different from that suggested by the cross-sectional data in this study. As observer bias is difficult to rule out from a practical point of view it may remain impossible to decide whether AMH levels really are superior to antral follicle counts, until use can be made of stored ultrasound scans on three-dimensional equipment (33). Because all endocrine markers, including $\mathrm{AMH}$, were assessed in the same run, their longitudinal change was not influenced by interassay variations.

The AMH levels showed the best consistency of change in individual women. A high correlation between the residuals of AMH levels at $T_{1}$ and $T_{2}$ was observed (Table 3). The $\mathrm{AFC}$ was second best in this regard. Although the number of follicles counted did not change over time (Table 1), the women maintained the same relative positions with respect to the mean level of their age group. The residuals of FSH and inhibin B levels showed a significant but clearly lower correlation. 


\section{FIGURE 1}

Spearman correlations of all ovarian reserve tests with age, at $T_{1}$ (red circles and continuous line) and $T_{2}$ (blue asterisks and dotted line). (A) Correlation of antimüllerian hormone with age at $\mathrm{T}_{1}(R=-0.66, P \leq .001)$ and at $\mathrm{T}_{2}(R=-0.65, P \leq .001)$. (B) Correlation of antral follicle count with age at $\mathrm{T}_{1}(R=-0.74, P \leq .001)$ and at $\mathrm{T}_{2}(R=-0.79, P \leq .001)$. (C) Correlation of $\mathrm{FSH}$ with age at $\mathrm{T}_{1}(R=0.35, P=.002)$ and at $\mathrm{T}_{2}(R=$ $0.60, P<.001$ ), for the relation of $\mathrm{FSH}$ with age a fitted line was used. (D) Correlation of inhibin $\mathrm{B}$ with age at $\mathrm{T}_{1}(R=-0.05, P=.65)$ and at $\mathrm{T}_{2}(R=-0.39, P \leq .001)$. (E-facing page) Correlation of $\mathrm{E}_{2}$ with age at $\mathrm{T}_{1}(R$ $=0.26, P=.02)$ and at $\mathrm{T}_{2}(R=-0.03, P=.82)$.
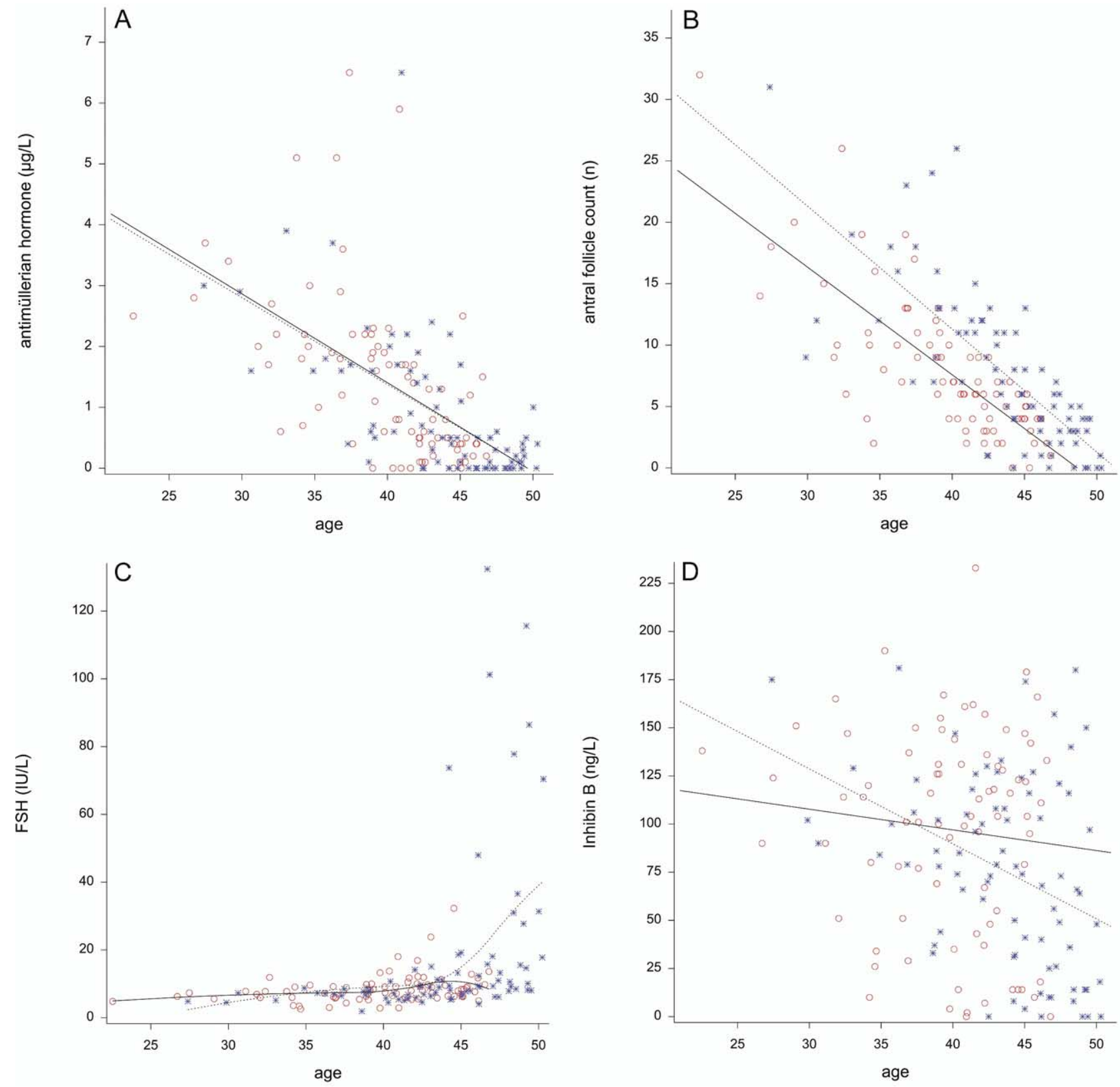

van Rooij. Serum AMH reflects female reproductive decline. Fertil Steril 2005.

In a much larger study with more observations per women, a sophisticated analysis was performed on the individual consistency of FSH and $\mathrm{E}_{2}$ in women during the menopausal transition (26). It was concluded that the resid- uals of FSH were moderately correlated over time and the residuals of $\mathrm{E}_{2}$ only weakly. Information regarding the individual consistency of inhibin B, AFC, and AMH were lacking in that study. One of the prerequisites for a high corre- 


\section{FIGURE 1 Continued}

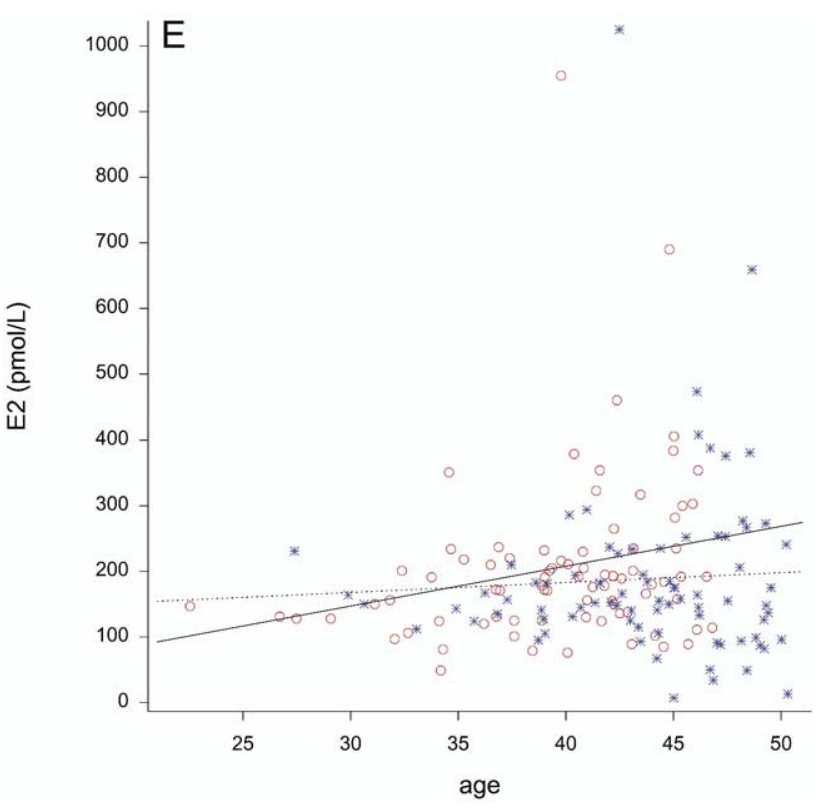

van Rooij. Serum AMH reflects female reproductive decline. Fertil Steril 2005.

lation between the residuals is a good cycle-to-cycle agreement. We have indications that the cycle-to-cycle variation of AMH levels is small in comparison with that of the other endocrine markers (van Rooij et al., unpublished observations).

Because AMH best fulfilled the criteria imposed, it better reflected the continuous decline of the oocyte/follicle pool with age than the other markers investigated. Because its serum levels decline in all age classes it appears to be the best marker of the gradual dwindling of follicle numbers. More important, as the changes over time in individuals show consistency with regard to the mean decline, AMH gives the most reliable reflection of individual reproductive aging and is expected to give better predictions with regard to the extent of decline in the future.

In the previous cross-sectional part of the study AFC was considered the best marker of reproductive age (19). Serum AMH levels were not included in that analysis, but would have come in as second best. Because AFC and AMH are highly correlated, it is plausible that both provide a good reflection of the declining follicle pool (14, $16,17)$. The AFC fulfilled the ovarian reserve marker characteristics, except for the decline over time, which was likely due to interobserver variability. In future longitudinal investigations stored ultrasound images using three-dimensional equipment could be used to assess the number of follicles over time by a single observer, thus eliminating interobserver variability (33).

Because we considered menopausal transition as part of the normal reproductive aging process, we included women

\section{TABLE 3}

Correlation of the residuals ${ }^{a}$ over time $\left(T_{1}\right.$ and $\mathrm{T}_{2}$ ).

\begin{tabular}{|lc|}
\hline & Residuals $\mathbf{T}_{\mathbf{1}}$ and $\mathbf{T}_{\mathbf{2}}$ \\
\hline AMH & $0.66^{\mathrm{b}}$ \\
AFC & $0.58^{\mathrm{b}}$ \\
FSH & $0.30^{\mathrm{b}}$ \\
Inhibin B & $0.37^{\mathrm{b}}$ \\
$\mathrm{E}_{2}$ & -0.05 \\
\hline
\end{tabular}

Note: Values are Pearson correlation coefficients.

${ }^{a}$ Residuals are age corrected values of ovarian reserve markers.

b $P<.01$.

van Rooij. Serum AMH reflects female reproductive decline. Fertil Steril 2005 .

whose cycle became irregular. Ovarian reserve tests are mainly useful in women still having regular cycles, as women who reach the menopausal transition are already infertile for several years (1). When excluding women, who had reached the menopausal transition at $\mathrm{T}_{2}, \mathrm{AMH}$ also best represented the change in reproductive capacity with age (results not shown). From Figure 1 it can be deducted that FSH increases only in a late stage and is therefore clinically less useful.

The study design on which ovarian reserve parameters were followed in a longitudinal fashion has been applied in a smaller, previous study from another Dutch research group (14). In that study a considerably shorter follow-up period was applied and the range of chronological ages of the volunteers was clearly narrower. The cohort consisted of relatively young women, which in majority did not have proven fertility in the past. As such that group may not have represented the best possible approximation of normal reproductive decline. In spite of this, the findings in both studies on AMH and AFC follow the same pattern and taken together provide mutual support for the conclusion that AMH best expresses the reproductive decline with age. In contrast, in the present study a clear decline in FSH and inhibin B levels with age was found, albeit in the later stages of reproductive life when cycle irregularity may already be present.

Serum AMH levels may be of value in clinical practice. The AMH has been shown to be a predictor of ovarian response in patients undergoing $\operatorname{IVF}(15,16)$, which can be regarded as a reflection of ovarian reserve (34). With AFC a similar prediction of ovarian response was obtained (16). It would be useful to investigate whether AMH or AFC could differentiate in the prognosis of women who are normally denied IVF treatment because of advanced age. Older patients with a normal response might still perform well in IVF, and AMH or AFC levels have the potential to detect such women (35). 
Qualitative assessment of the fulfillment of criteria investigated for each ovarian reserve test.

\begin{tabular}{|lccccc|}
\hline & AMH & AFC & FSH & Inhibin B & $\mathbf{E}_{\mathbf{2}}$ \\
\hline Biologically plausible & +++ & $++/+++$ & ++ & $++/+++$ & + \\
Cross-sectional relation with age (Fig. 1) & $++/+++$ & +++ & ++ & + & - \\
Mean longitudinal decline (Table 1 and 2) & +++ & + & $+/++$ & $+/++$ & - \\
Consistency of individual change (Table 3) & +++ & $++/+++$ & + & + & -
\end{tabular}

Note: +++ , good; ++ , reasonable; + , weak; - , no.

a Present in the entire range of ages.

${ }^{\mathrm{b}}$ As assessed by correlation of the residuals.

van Rooij. Serum AMH reflects female reproductive decline. Fertil Steril 2005.

Another application of the ovarian reserve tests may involve the prediction of cycle irregularity or the final menstrual period. Due to the large individual variation, a single measurement of FSH or $\mathrm{E}_{2}$ appears not to be able to reliably detect the reproductive status of an individual woman (26). Because serum AMH levels and the number of antral follicles decline more gradually with age, they may better predict the occurrence of the menopausal transition.

In summary, we consider serum AMH levels to be the best marker reflecting the decline of reproductive aging. Useful clinical applications of AMH seem feasible.

\section{REFERENCES}

1. te Velde ER, Pearson PL. The variability of female reproductive ageing. Hum Reprod Update 2002;8:141-54.

2. Faddy MJ, Gosden RG, Gougeon A, Richardson SJ, Nelson JF. Accelerated disappearance of ovarian follicles in mid-life: implications for forecasting menopause. Hum Reprod 1992;7:1342-6.

3. Treloar AE. Menstrual cyclicity and the pre-menopause. Maturitas 1981;3:249-64.

4. Sherman BM, West JH, Korenman SG. The menopausal transition: analysis of LH, FSH, estradiol, and progesterone concentrations during menstrual cycles of older women. J Clin Endocrinol Metab 1976;42: 629-36.

5. Fauser BC, Van Heusden AM. Manipulation of human ovarian function: physiological concepts and clinical consequences. Endocrinol Rev 1997;18:71-106.

6. Klein NA, Illingworth PJ, Groome NP, McNeilly AS, Battaglia DE, Soules MR. Decreased inhibin B secretion is associated with the monotropic FSH rise in older, ovulatory women: a study of serum and follicular fluid levels of dimeric inhibin A and B in spontaneous menstrual cycles. J Clin Endocrinol Metab 1996;81:2742-5.

7. Welt CK, McNicholl DJ, Taylor AE, Hall JE. Female reproductive aging is marked by decreased secretion of dimeric inhibin. J Clin Endocrinol Metab 1999;84:105-11.

8. Klein NA, Battaglia DE, Fujimoto VY, Davis GS, Bremner WJ, Soules MR. Reproductive aging: accelerated ovarian follicular development associated with a monotropic follicle-stimulating hormone rise in normal older women. J Clin Endocrinol Metab 1996;81:1038-45.

9. MacNaughton J, Banah M, McCloud P, Hee J, Burger H. Age related changes in follicle stimulating hormone, luteinizing hormone, oestradiol and immunoreactive inhibin in women of reproductive age. Clin Endocrinol (Oxf) 1992;36:339-45.

10. Pache TD, Wladimiroff JW, de Jong FH, Hop WC, Fauser BCJM. Growth patterns of nondominant ovarian follicles during the normal menstrual cycle. Fertil Steril 1990;54:638-42.
11. Scheffer GJ, Broekmans FJ, Dorland M, Habbema JD, Looman CW, te Velde ER. Antral follicle counts by transvaginal ultrasonography are related to age in women with proven natural fertility. Fertil Steril 1999;72:845-51.

12. Durlinger AL, Visser JA, Themmen AP. Regulation of ovarian function: the role of anti-Mullerian hormone. Reproduction 2002;124:601-9.

13. Rey R, Sabourin JC, Venara M, Long WQ, Jaubert F, Zeller WP, et al. Anti-Mullerian hormone is a specific marker of sertoli- and granulosacell origin in gonadal tumors. Hum Pathol 2000;31:1202-8.

14. de Vet A, Laven JSE, de Jong FH, Themmen APN, Fauser BCJM. Anti-Mullerian hormone serum levels: a putative marker for ovarian aging. Fertil Steril 2002;77:357-62.

15. Seifer DB, MacLaughlin DT, Christian BP, Feng B, Shelden RM. Early follicular serum mullerian-inhibiting substance levels are associated with ovarian response during assisted reproductive technology cycles. Fertil Steril 2002;77:468-71.

16. Van Rooij IA, Broekmans FJ, te Velde ER, Fauser BC, Bancsi LF, Jong FH, et al. Serum anti-Mullerian hormone levels: a novel measure of ovarian reserve. Hum Reprod 2002;17:3065-71.

17. Fanchin R, Schonauer LM, Righini C, Guibourdenche J, Frydman R, Taieb J. Serum anti-Mullerian hormone is more strongly related to ovarian follicular status than serum inhibin B, estradiol, FSH and LH on day 3. Hum Reprod 2003;18:323-7.

18. Fanchin R, Schonauer LM, Righini C, Frydman N, Frydman R, Taieb J. Serum anti-Mullerian hormone dynamics during controlled ovarian hyperstimulation. Hum Reprod 2003;18:328-32.

19. Scheffer GJ, Broekmans FJ, Looman CW, Blankenstein M, Fauser BC, de Jong FH, et al. The number of antral follicles in normal women with proven fertility is the best reflection of reproductive age. Hum Reprod 2003; 18:700-6.

20. Mitchell ES, Woods NF, Mariella A. Three stages of the menopausal transition from the Seattle Midlife Women's Health Study: toward a more precise definition. Menopause 2000;7:334-49.

21. Soules MR, Sherman S, Parrott E, Rebar R, Santoro N, Utian W, et al. Executive summary: Stages of Reproductive Aging Workshop (STRAW) Park City, Utah, July 2001. Menopause 2001;8:402-7.

22. Groome NP, Illingworth PJ, O'Brien M, Pai R, Rodger FE, Mather JP, et al. Measurement of dimeric inhibin B throughout the human menstrual cycle. J Clin Endocrinol Metab 1996;81:1401-5.

23. Long WQ, Ranchin V, Pautier P, Belville C, Denizot P, Cailla H, et al. Detection of minimal levels of serum anti-Mullerian hormone during follow-up of patients with ovarian granulosa cell tumor by means of a highly sensitive enzyme-linked immunosorbent assay. J Clin Endocrinol Metab 2000;85:540-4.

24. Lee MM, Donahoe PK, Hasegawa T, Silverman B, Crist GB, Best S, et al. Mullerian inhibiting substance in humans: normal levels from infancy to adulthood. J Clin Endocrinol Metab 1996;81:571-6.

25. Wegman EJ, Wright IW. Splines in statistics. JASA 1983;78:351-65.

26. Burger HG, Dudley EC, Hopper JL, Groome N, Guthrie JR, Green A, et al. Prospectively measured levels of serum follicle-stimulating hor- 
mone, estradiol, and the dimeric inhibins during the menopausal transition in a population-based cohort of women. J Clin Endocrinol Metab 1999;84:4025-30.

27. Kachigan SK. Partial correlation. In: Kachigan SK, ed. Statistical analysis. An interdisciplinary introduction to univariate and multivariate methods. 2nd ed. New York: Radius Press, 1986:232-3.

28. Baarends WM, Uilenbroek JT, Kramer P, Hoogerbrugge JW, van Leeuwen $\mathrm{C}$, Themmen AP, et al. Anti-mullerian hormone and anti-mullerian hormone type II receptor messenger ribonucleic acid expression in rat ovaries during postnatal development, the estrous cycle, and gonadotropininduced follicle growth. Endocrinology 1995;136:4951-62.

29. Weenen C, Laven JS, Von Bergh AR, Cranfield M, Groome NP, Visser JA, et al. Anti-Mullerian hormone expression pattern in the human ovary: potential implications for initial and cyclic follicle recruitment. Mol Hum Reprod 2004;10:77-83.

30. Schipper I, de Jong FH, Fauser BC. Lack of correlation between maximum early follicular phase serum follicle stimulating hormone concentrations and menstrual cycle characteristics in women under the age of 35 years. Hum Reprod 1998;13:1442-8.
31. Klein NA, Harper AJ, Houmard BS, Sluss M, Soules MR. Is the short follicular phase in older women secondary to advanced or accelerated dominant follicle development? J Clin Endocrinol Metab 2002;87: $5746-50$.

32. Hansen KR, Morris JL, Thyer AC, Soules MR. Reproductive aging and variability in the ovarian antral follicle count: application in the clinical setting. Fertil Steril 2003;80:577-83.

33. Scheffer GJ, Broekmans FJ, Bancsi LF, Habbema JD, Looman CW, te Velde ER. Quantitative transvaginal two- and three-dimensional sonography of the ovaries: reproducibility of antral follicle counts. Ultrasound Obstet Gynecol 2002;20:270-5.

34. Beckers NG, Macklon NS, Eijkemans MJ, Fauser BC. Women with regular menstrual cycles and a poor response to ovarian hyperstimulation for in vitro fertilization exhibit follicular phase characteristics suggestive of ovarian aging. Fertil Steril 2002;78:291-7.

35. Roest J, van Heusden AM, Mous H, Zeilmaker GH, Verhoeff A. The ovarian response as a predictor for successful in vitro fertilization treatment after the age of 40 years. Fertil Steril 1996;66:969-73. 